\title{
Sistema de ejercicios a partir del cuento Francisca y la muerte, de Onelio Jorge Cardoso
}

\author{
System of exercises by studying the story Francisca and death, \\ by Onelio Jorge Cardoso
}

\author{
Yelenny Molina Jiménez \\ Universidad de Moa, Cuba \\ Tania Bess Reyes \\ Universidad de Moa, Cuba
}

\begin{abstract}
Resumen: Se concibió un sistema de ejercicios a partir del cuento Francisca y la muerte, de Onelio Jorge Cardoso, regido por el enfoque cognitivo, comunicativo y sociocultural que integra los contenidos gramaticales, léxicos y pragmáticos en función de los culturales. Para ello, se usaron los métodos y técnicas: Histórico-lógico, Hermenéutico, Análisis-síntesis, Sistémico-estructural y la encuesta a especialistas y expertos. Se elaboró la descripción metodológica de los ejercicios para orientar el trabajo del profesor. La propuesta didáctica constituye una guía para la sistematización del enfoque tomado como referencia en la práctica cotidiana de la enseñanza del español como lengua extranjera.
\end{abstract}

Palabras clave: sistema de ejercicios, enfoque cognitivo, comunicativo y sociocultural, contenidos gramaticales, enseñanza del español como lengua extranjera.

Abstract: The paper presents a system of exercises, concerning Onelio Jorge Cardoso's story Francisca and death, regulated by the cognitive, communicative and socio-cultural approach that integrates grammatical, lexical and pragmatic contents based on cultural ones. The following methods and techniques were used in this study: historical-logical, hermeneutic, analysis-synthesis, systemic-structural as well as a survey of specialists and experts. The methodological description of the exercises was elaborated to guide the teacher's work. The didactic proposal constitutes a guide for the systematization of the approach taken as a reference in the daily practice of teaching Spanish as a Foreign Language.

Keywords: system of exercises, cognitive, communicative and socio-cultural approach, grammatical contents, teaching Spanish as a Foreign Language.

\section{Introducción}

Enseñar lengua usando como soporte a la literatura no ha sido una práctica muy sistemática en las clases de Español como lengua extranjera (ELE), aunque existen investigaciones que avalan su uso en alguna medida. Tal es el caso de las realizadas por Jouini (2008), Menouer (2009) y Funes (2012), entre otras. 
Sin embargo, se considera que desaprovechar las potencialidades que ofrece la literatura para captar los recursos de la lengua en su uso efectivo, limita la obtención de válidos ejemplos del habla, la conformación del conocimiento cultural, sociocultural e intercultural y el disfrute del placer de la lectura por parte de los estudiantes extranjeros (Sitman \& Lerner, 1994; Sanz, 2002; Aventín, 2005; Sanz, 2006; Vergara, 2006; Albaladejo, 2007; Jouini, 2008; López, 2000; Stembert, 2009; Durán, 2010; Bernal, 2011; Berná, 2013; Cardona, 2014).

Actualmente, aunque existen varios criterios favorables en cuanto al empleo del texto literario como recurso didáctico en las clases de español como lengua extranjera e, incluso, se advierte cierto intento por incorporarlo en los libros de trabajo; realmente, en la práctica, este solo aparece al final de las unidades didácticas como un complemento carente de sentido funcional $y$, en muchas ocasiones, los contenidos gramaticales se encuentran desligados de los culturales. Las muestras se proyectan más hacia la sustentación teórica que a la fundamentación de una praxis integradora.

Por ello, con esta investigación se sugiere aprovechar al máximo el texto literario, en todas sus dimensiones, de forma tal que constituya una herramienta útil y asidua en el proceso de enseñanza-aprendizaje de la lengua y la cultura cubana. Este permite fomentar el hábito de la lectura; mostrar aspectos de la cultura de la lengua meta; enriquecer el vocabulario de los alumnos; reconocer las variantes lingüísticas y sociolingüísticas del español; proporcionar un acercamiento a la literatura y transmitir su valor cultural; provocar un ambiente idóneo para el desarrollo de situaciones comunicativas donde el alumno integra las capacidades lingüísticas, sociales y culturales; así como, desarrollar estrategias lectoras.

Como el modo más acertado para lograrlo, se asume el enfoque cognitivo, comunicativo y sociocultural de Roméu (2003), surgido en Cuba en el contexto de la enseñanza de la lengua materna y aplicado en ELE con excelentes resultados (Medina, 2008; Toledo, 2006). Entre los trabajos que lo evidencian están las investigaciones desarrolladas en la Facultad de Español para No Hispanohablantes de la Universidad de La Habana por Chillón (2011) y Torres (2011), citados por Dueñas (2012).

Este enfoque constituye fundamento metodológico de una gramática del habla o discursiva y uno de los principios teóricos que lo sustenta es la relación entre el discurso, la cognición y la sociedad. Se fundamenta en la concepción dialécticomaterialista acerca del lenguaje, el cual se alcanza a través de la interacción social y se nutre de las principales fuentes lingüísticas del siglo XX y de las investigaciones más recientes de la lingüística del habla.

Tomando como pauta dicho enfoque se pretende ofrecer un sistema de ejercicios basado en el cuento Francisca y la muerte (ver anexo 1), de Onelio Jorge Cardoso, que integre los contenidos gramaticales, léxicos y pragmáticos en función de los culturales.

\section{Desarrollo}

Con el advenimiento del enfoque comunicativo, la enseñanza de lengua le ha otorgado un papel preponderante al contexto y al componente sociocultural. En la actualidad, cobran gran prioridad las necesidades del alumno a la hora de 
enfrentarse a las dificultades de tipo cultural que pueden surgir en la vida cotidiana del país extranjero. Pues, si bien es cierto que es importante que el estudiante se comunique con fluidez esto no le garantiza en su totalidad la eficacia del acto comunicativo, porque se le pueden presentar situaciones concretas, cuyo significado no podrá encontrar en un diccionario.

Es por ello que estos necesitan conocer la lengua en funcionamiento, lo que supone el aprendizaje de los códigos de interacción para comprender las actitudes, las reacciones y el comportamiento de los hablantes en cada situación.

Es precisamente en ese intercambio de contenidos culturales que se produce un aprendizaje significativo; de ahí la importancia de llevar a las aulas aspectos de la cotidianidad, que caracterizan a un individuo de una sociedad determinada, con la cual comparte costumbres, tradiciones, maneras de decir y hacer.

Con este propósito, se deberán articular las tres dimensiones del enfoque tomado como referencia (Roméu, 2006): la cognitiva, la comunicativa y la sociocultural. Bajo esta concepción metodológica se sustenta la presente investigación, a partir del empleo del texto literario, específicamente del cuento Francisca y la muerte, de Onelio Jorge Cardoso, concebido como macro texto para propiciar, en primera instancia, el enfoque cognitivo a través de la referencia sobre el autor y del proceso de lectocomprensión para expresar la concepción de mundo.

En segunda instancia, se transita del macro texto al micro texto al focalizar las características del discurso, en correspondencia con los rasgos distintivos presentes que tipifican a la sociedad cubana y que pueden ser objeto del conocimiento sociocultural, mediante el desarrollo de la competencia comunicativa.

Para ello se sugieren actividades que, en general, están concebidas para que el alumno responda teniendo como base el español hablado en Cuba; salvo algunas excepciones que tendrá que traer a colación respuestas propias de su lengua materna que servirán para propiciar la interculturalidad, la comparación de puntos de vistas y el debate en el grupo.

La propuesta demanda de una aproximación con el sistema de convenciones y normas de la cultura meta a través del aprendizaje consciente de los alumnos. Posee carácter interdisciplinario por la integración de teorías lingüísticas y didácticas para dar atención a los procesos implicados en la comprensión y construcción de significados, es flexible y está abierta a múltiples adaptaciones.

El profesor podrá dosificar, seleccionar, modificar o crear nuevos ejercicios, incluso variar el orden de los mismos en dependencia del objetivo de la clase. Las actividades pueden ser parte de una clase, la clase entera, o puede emplearse en más de una, de acuerdo con los objetivos del profesor y las necesidades de los estudiantes.

En el diseño de las actividades se tuvo en cuenta que contribuyeran a que el estudiante adquiera la dimensión cultural' que está conformada por los referentes culturales, los saberes y comportamientos socioculturales y las habilidades

\footnotetext{
1 Plan Curricular del Instituto Cervantes. Centro Virtual Cervantes. Disponible en: http://cvc.cervantes.es/ensenanza/biblioteca_ele/plan_curricular/default.htm [consultado el 12 de septiembre de 2019]
} 
interculturales ${ }^{2}$. Al analizar los dos primeros factores, Pinar (2012) define los referentes culturales como aquellos elementos, imágenes, ideas, realidades y productos culturales comunes y compartidos por la comunidad.

Mientras que los saberes y comportamientos socioculturales comprenden el modo y condiciones de vida, las convenciones sociales, realidades, valores, creencias, usos y costumbres, así como la identidad colectiva y las relaciones personales que determinan los usos y costumbres de los miembros de una sociedad y que pueden ser considerados como señas de identidad.

Sobre la base del inventario de contenidos de referentes culturales y saberes y comportamientos socioculturales del Plan Curricular del Instituto Cervantes y de los aspectos relacionados en el Marco Común Europeo de Referencia para las Lenguas, con respecto al conocimiento sociocultural, se conformó un sumario de los contenidos culturales que se abordan en esta investigación (Figura 1).

Estos no constituyen una pormenorización detallada y mucho menos concluida, pues con la aplicación de la propuesta didáctica puede enriquecerse mucho más. Lo cierto es que el conocimiento de estos aspectos es fundamental para que el estudiante sepa seleccionar los aspectos lingüísticos, el registro y la actitud adecuados para cada situación y logre una comunicación eficaz.

Sin menospreciar los estereotipos culturales que conoce el estudiante no hispanohablante, el profesor podrá apoyarse en las actividades para enseñarle las diferentes prácticas culturales habituales, aquellas que forman parte de la cotidianidad del cubano común. Por ejemplo, las formas de saludarse, los gustos culinarios, los rituales, los horarios, las maneras de transportarse (hacer botella), la dualidad monetaria, la manía imperante de hacer cola, el significado de los gestos y todo aquello que contribuya a que el alumno alcance una comprensión más amplia y profunda de la forma de vida y las formas de pensamiento de otros pueblos y de sus patrimonios culturales. 2 Álex G. Pinar: Cultura y publicidad en la clase de ELE. Propuesta didáctica para un curso de
conversación. MarcoELE No. 14, p.10. 


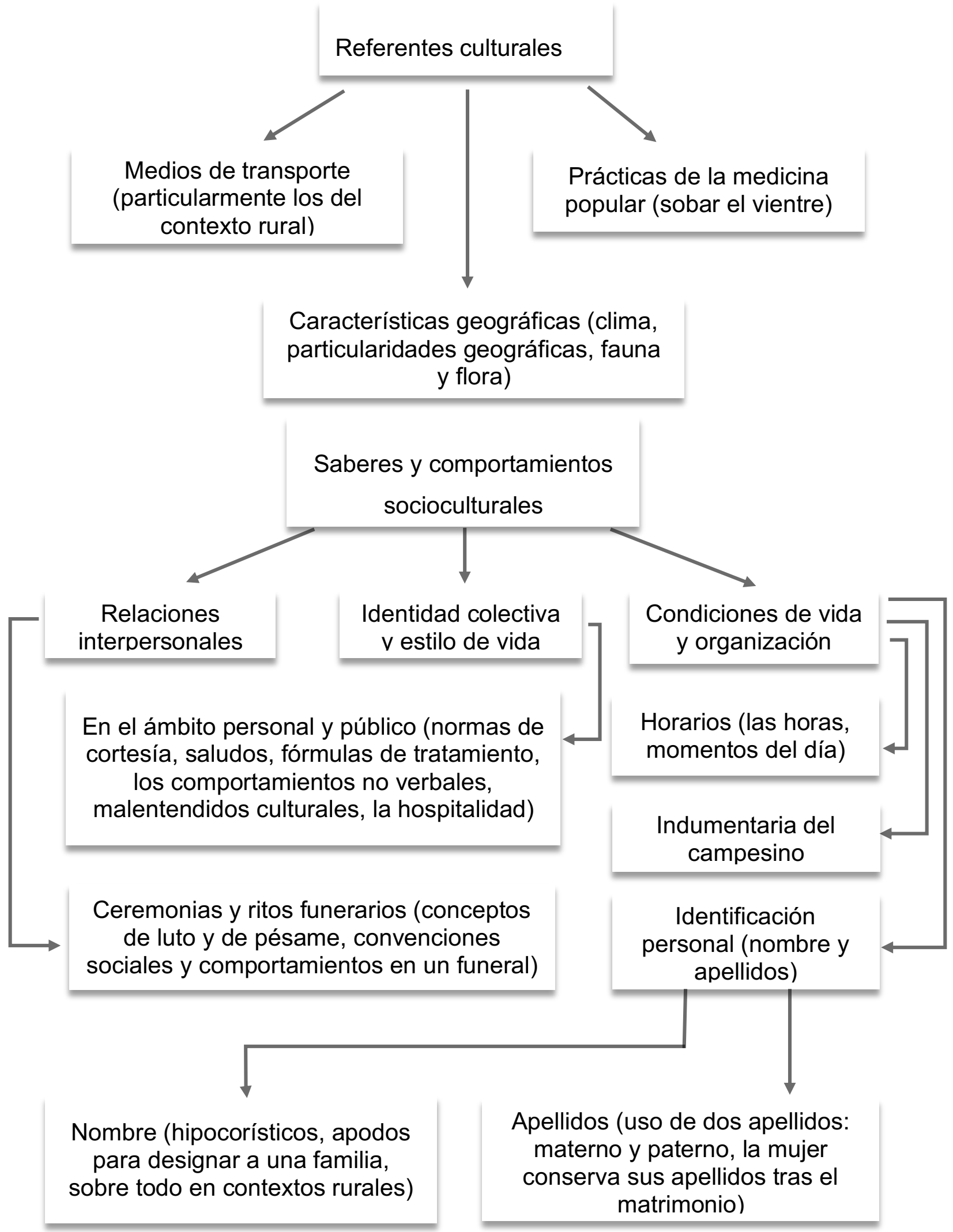

Figura 1. Sumario de contenidos culturales abordados en esta investigación (adaptado del inventario de contenidos de referentes culturales y saberes y comportamientos socioculturales del Plan Curricular del Instituto Cervantes). 
El sistema de ejercicios que se propone cuenta con los siguientes componentes metodológicos generales:

\section{OBJETIVOS GENERALES:}

Identificar los rasgos culturales reflejados en el cuento Francisca y la muerte, de Onelio Jorge Cardoso, apoyándose en el análisis de los contenidos gramaticales, léxicos y pragmáticos para contribuir a una mejor inserción de los estudiantes de ELE en la sociedad cubana.

Brindar a los profesores una herramienta útil, que contribuya a la adquisición de contenidos culturales en alumnos no hispanohablantes y al desarrollo de su competencia comunicativa, como propósito sustancial de la enseñanza de ELE.

\section{CONTENIDOS:}

- Léxicos: vocabulario relacionado con el campo semántico de la campiña, hiperónimos-hipónimos.

- Gramaticales: familia de palabras, frases hechas, sustantivos, sintagmas nominales, sintagma verbal, diminutivos, interjecciones, palabras que pueden escribirse de diferentes formas, signos de puntuación, pronombres, adverbios, polisemia de la lengua española.

- Culturales: labores agrícolas, vestimenta de los campesinos, cualidades y valores del campesinado, la hospitalidad, características de la geografía cubana, convenciones y comportamientos sociales en cuanto al nombre y apellidos, hipocorísticos, normas de cortesía, formas de tratamiento, prácticas de la medicina popular, expresiones coloquiales, medios de transporte, malentendidos culturales, formas rituales, las horas, partes del día, diferencias diatópicas del habla, ritos funerarios.

- Pragmáticos: lenguaje no verbal (kinésica), normas de cortesía, formas de tratamiento (uso de tú y usted), atenuación.

3. MÉTODOS:

- productivo;

- investigativo;

- conversación heurística.

\section{PROCEDIMIENTOS:}

- trabajo con el diccionario;

- trabajo con las imágenes;

- trabajo con el texto;

- trabajo independiente;

- trabajo en grupo;

- dramatización;

- actividad creadora;

- lectura en silencio; 
- lectura dramatizada;

- explicación.

5. MEDIOS: pizarra, tarjetas, láminas, computadora, diccionarios, mural, la voz del profesor.

A continuación se presenta el sistema de ejercicios propuesto:

\section{Actividades de prelectura}

\section{1. ¿Qué te sugieren las siguientes imágenes?}

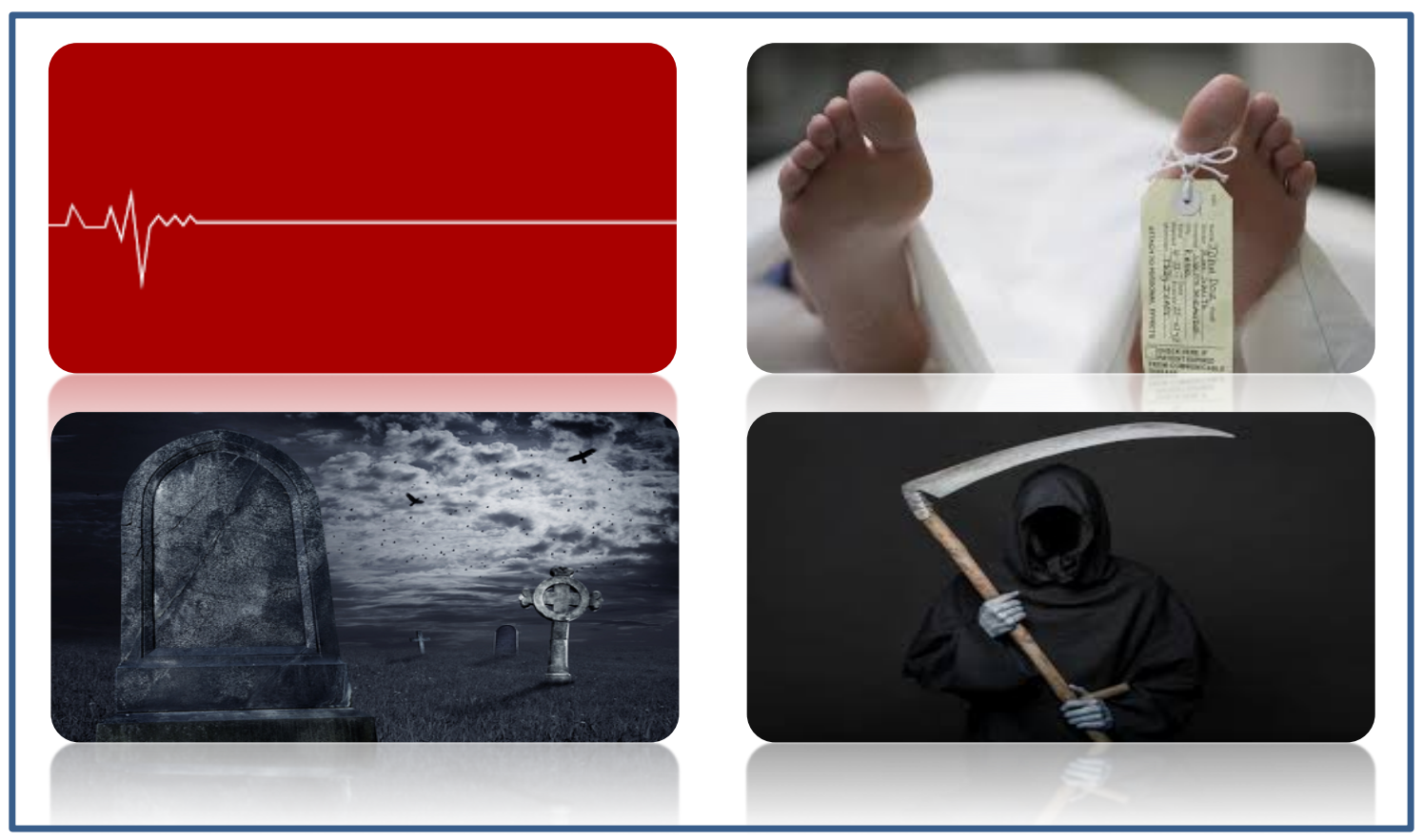

a) ¿Cómo se asume la muerte de un ser querido en tu país?

b) ¿Cómo le manifestarías tu dolor a una persona que ha perdido recientemente a un familiar?

c) Si tuvieras que burlar la muerte, ¿̇cómo lo harías? Intercambia tus criterios con los de tus compañeros.

Descripción de la actividad: este es un ejercicio preparatorio. Se les muestra a los estudiantes imágenes alegóricas a la muerte y luego de preguntarles lo que representan se les incita a hablar sobre cómo se asume, desde sus culturas, la pérdida de ser querido. El ejercicio permite, a través de la comparación y los distintos puntos de vistas, mostrar una visión intercultural del tema de la muerte, mediante el 
tratamiento de contenidos culturales relacionados con las ceremonias y ritos funerarios. La actividad se desarrolla de forma oral.

\section{Observa las siguientes imágenes y luego responde:}

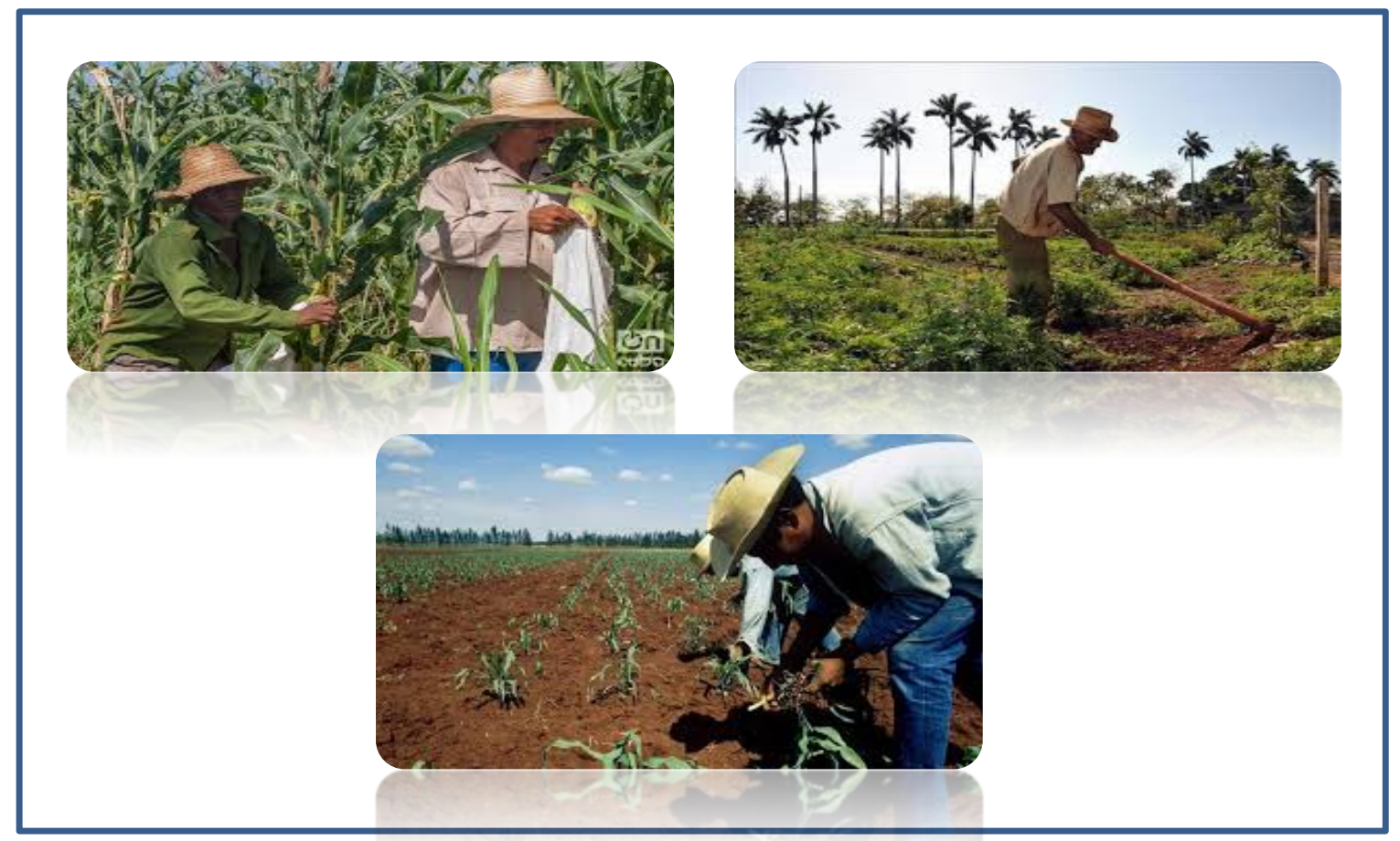

a) ¿Qué hacen esos hombres?

b) ¿Qué nombre reciben los hombres que realizan esas actividades?

c) Fíjate en su vestimenta. ¿A qué crees que se deba el uso de la misma?

d) Comenta con tus compañeros cuáles elementos del clima, la naturaleza o la geografía cubana les resultan más atractivos.

Descripción de la actividad: esta actividad de expresión oral posibilita el trabajo con los términos sinonímicos labrador, campesino, además permite introducir un nuevo vocablo, "guajiro", que se utiliza específicamente para nombrar al campesino de Cuba. Se trabajan los contenidos culturales relacionados con la indumentaria de los campesinos cubanos para realizar sus labores agrícolas y, relacionado con esto también, las características climáticas y geográficas de Cuba. 
3. El cuento que vas a leer se titula Francisca y la muerte. ¿Qué te insinúa ese título?

Descripción de la actividad: mediante una lluvia de ideas con las respuestas aportadas por los estudiantes se conforma, entre todos, un posible argumento. Este ejercicio está destinado a crear expectativas sobre el texto y mantener la motivación de los estudiantes. Propicia el trabajo en colectivo.

4. ¿Te atreves a predecir cuál será el final del cuento? Escribe tu versión en una tarjeta y entrégasela a tu profesor.

Descripción de la actividad: el profesor indica las orientaciones y el estudiante realiza la actividad de forma individual. El docente reservará las tarjetas para, después de la lectura del cuento, seleccionar el desenlace que más se acerca a la realidad así como la versión más original. Se propicia el desarrollo de la creatividad de los alumnos.

\section{Actividades durante la lectura}

5. Realiza una lectura en silencio del cuento Francisca y la muerte. Explica por qué la muerte no encontró a Francisca.

a) Extrae las expresiones que lo evidencian.

Descripción de la actividad: con el ejercicio se abordan las faenas propias que se realizan en el campo, y al mismo tiempo, se hace referencia a la laboriosidad como característica esencial de los campesinos. Permite, además, comprobar si los estudiantes comprendieron el texto.

\section{Realiza una lectura en silencio del cuento Francisca y la muerte.}

¿Qué estaba haciendo Francisca en casa de los Noriegas? Coméntale a tus compañeros lo que sabes sobre esta práctica.

Descripción de la actividad: este ejercicio propicia la activación de conocimientos previos al exigir al estudiante el uso de las estrategias de lecturas que trae incorporadas desde su lengua materna para desarrollar la comprensión escrita. Se introduce una práctica cultural que forma parte de la creencia popular del cubano.

\section{7. ¿Cómo explicarías con tus propias palabras las siguientes expresiones del texto?:}

Seguir dando rueda: 
Como un disparo:

Hecha una lástima:

No había un alma:

Sin tino:

Apretó el paso:

Descripción de la actividad: este ejercicio prepara al estudiante para el trabajo con el vocabulario del cuento. Exige que el alumno haga inferencias que luego serán constatadas durante el análisis de las expresiones en el contexto. Posibilita la apropiación de expresiones del lenguaje coloquial.

\section{8. ¿Cuáles términos te resultan desconocidos? Auxíliate del diccionario y pide ayuda a tu profesor para conocer su significado.}

Descripción de la actividad: este ejercicio familiariza al estudiante con el cuento, constituye su primer acercamiento. Permite identificar los términos que les resulten desconocidos.

\section{Localiza en el texto las expresiones que indiquen:}

I. Sentir repugnancia

II. Sentir enojo

a) ¿Con qué otros gestos lo expresarías tú?

b) Improvisa con un compañero una situación comunicativa donde este tenga que hacer uso del lenguaje no verbal, luego de descifrarlo expresa su significado en una frase.

c) ¿Qué significado le atribuyes a los siguientes gestos?

Señalar con el dedo:

D. Mirar la hora:

- Meter la mano en los bolsillos:

d) ¿̇Conoces qué connotación puede tener mirar la hora reiteradamente en un breve periodo de tiempo? Comenta tu punto de vista con tus compañeros.

e) ¿Cómo reforzarías la intención comunicativa de las siguientes frases?

$\checkmark$ ¡Quién lo sabe!

$\checkmark$ Allá por las cañas bravas

$\checkmark$ ¡Contra! 
f) ¿̇Has sufrido algún malentendido, desde tu llegada a Cuba, por culpa de algún gesto inapropiado que te hayan hecho o tu hayas realizado? Comenta tu experiencia con tus compañeros.

Descripción de la actividad: el ejercicio permite el trabajo con contenidos pragmáticos relacionados con la comunicación no verbal. Se enfatiza en la kinésica, a través del empleo de los gestos en el lenguaje conversacional. Con ello se persigue que el estudiante se apropie de estos conocimientos pragmáticos para que se comunique de forma eficaz. También el ejercicio posibilita el estudio de los malentendidos, que por desconocimiento de aspectos socioculturales, dificultan la comunicación. Esta actividad fomenta la creatividad de los estudiantes y el trabajo en dúo.

10. Extrae la frase que da inicio all cuento.

a) ¿Por qué consideras que se ha utilizado?

b) ¿Qué estructura gramatical la conforma?

c) ¿Conoces otras expresiones que cumplan igual función comunicativa?

d) Identifica otras estructuras gramaticales que constituyan normas de cortesía.

e) ¿Qué características le confiere su uso al campesinado cubano?

Descripción de la actividad: el ejercicio facilita el acercamiento a los contenidos pragmáticos, mediante el reconocimiento y análisis de las expresiones de cortesía presentes en el cuento. Se profundiza en las funciones comunicativas que estas desempeñan así como en el carácter atenuador que manifiestan durante el acto conversacional.
11. Extrae las expresiones que contribuyen a describir el clima de la temporada.
a) Clasifica las que constituyan recursos literarios.
b) ¿̇Por qué han sido empleadas?
C) ¿Cómo describirías tu estación del año preferida?

Descripción de la actividad: el ejercicio contribuye a que los estudiantes se apropien de contenidos culturales relacionados con las características climáticas de Cuba y con creencias populares (con respecto a tomar agua de mayo) que forman parte de la tradición del cubano. Permite, además, el trabajo con expresiones del lenguaje figurado, lo que enriquece el vocabulario de los alumnos. 
12. Selecciona a un compañero de clases y realiza la lectura dramatizada del siguiente fragmento:

«CContra!», pensó la muerte, «se me irá el tren de las cinco. No; mejor voy a buscarla». Y levantando su voz, dijo la muerte:

- ¿Dónde, al fijo, pudiera encontrarla ahora?

- De madrugada salió a ordeñar. Seguramente estará en el maíz, sembrando.

a) ¿Con qué tipo de palabra comienza el fragmento? ¿Cuál es la intención comunicativa que posee?

b) Localiza en el texto otras expresiones similares y comenta con tus compañeros cuál es la peculiaridad que las distingue y por qué crees que suceda esto.

c) Extrae la parte del fragmento donde se hace referencia a una de las labores que se realizan en los campos cubanos. ¿Qué conoces de esta faena?

d) Sustituye por un adverbio la expresión subrayada. ¿̇Por qué crees que se ha empleado este signo de puntuación y no otro?

e) Expón, a través de ejemplos, otros usos de la coma que conozcas.

f) Reelabora la última oración de tal forma que reemplaces al vocablo que presenta un sufijo por su adjetivo equivalente.

Descripción de la actividad: el ejercicio permite abordar la intención comunicativa de las oraciones exclamativas e interrogativas. Posibilita tratar el uso de la coma y contribuir al aprendizaje de la ortografía puntual. Como contenido cultural se hace alusión a las faenas que se realizan en el campo y, específicamente en el caso del ordeño, se puede hacer referencia al momento del día en que acontece esta costumbre campesina.

\section{Pronuncia las siguientes palabras extraídas del texto:}

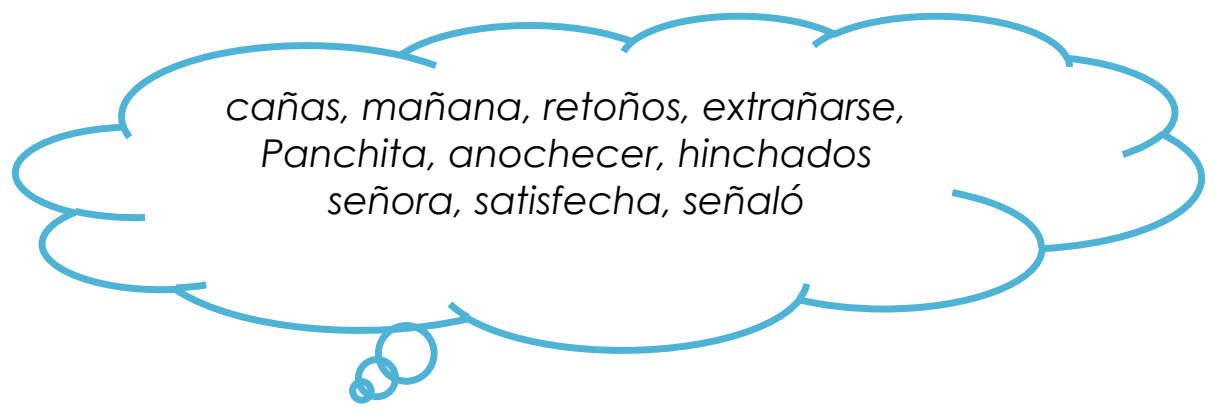

a) ¿Cómo clasificarías la quinta palabra?

b) ¿Sabes de cuál sustantivo propio proviene? ¿̇De qué otra forma se llaman las que llevan este nombre? 
c) ¿Con qué intención crees que se empleó en el texto este término y no el que le da origen?

d) ¿¿Qué otros nombres propios aparecen en el texto? ¿QQué te resulta curioso de estos?

Descripción de la actividad: el ejercicio posibilita la pronunciación de vocablos que contengan la letra ñ y el dígrafo ch, con el objetivo de contribuir a mejorar la dicción de los estudiantes.

Por otra parte, se trabajan los contenidos culturales relacionados con la identificación personal: los hipocorísticos, el uso del apellido antecedido del artículo los para referirse a los miembros de una familia. Posibilita el trabajo con el término señora y su forma de uso e introducir la preferencia del vocablo compañero. También permite abordar las convenciones sociales en cuanto al uso del nombre y el apellido que fueron reflejadas en el epígrafe anterior.

Con la orientación del inciso c) el profesor puede referirse a la función apelativa del diminutivo, en el contexto donde aparece, como estrategia pragmática para establecer cercanía con el interlocutor y contribuir a la consecución de su objetivo.

\section{Lee el siguiente fragmento:}

Anduvo y anduvo. En casa de los González le dijeron que estaba Francisca a un tiro de ojo de allí, cortando pangola para la vaca de los nietos. Mas, sólo vio la muerte la pangola recién cortada y nada de Francisca, ni siquiera la huella menuda de su paso.

a) ¿Con qué finalidad crees que el autor empleó en el fragmento una oración que responde a la estructura: forma verbal + conjunción + forma verbal?

b) ¿Por cuál palabra sustituirías el sintagma nominal empleado por los González para ofrecer la ubicación de Francisca?

c) ¿Conoces otras frases similares usadas por los campesinos con igual significado?

d) ¿̇ué otras expresiones conoces que se formen a partir del primer sustantivo del sintagma analizado?

e) En el fragmento aparece un término cuya escritura no obedece a las nuevas regulaciones de la ortografía de la lengua española, emitidas por la Real Academia Española en el 2010. ¿̇Puedes identificarlo y comentar en qué consiste el cambio? Localiza en el resto del texto otro caso similar.

Descripción de la actividad: el ejercicio permite hacer referencia a la reiteración como recurso empleado en el habla popular para reforzar la intención comunicativa del enunciado. Se abordan contenidos culturales relacionados con expresiones coloquiales muy comunes en el habla de los campesinos cubanos. Se fomenta el trabajo con la ortografía, específicamente con el acento y se actualiza al estudiante de las nuevas disposiciones ortográficas sobre los términos esa y solo. 
15. Localiza el fragmento del cuento donde se emplea un diminutivo para indicar la ubicación de Francisca.

a) Indica la estructura correcta que presenta el sintagma verbal que te permite conocer la acción que realizaba Francisca allí.

_ forma verbal + conjunción + sustantivo + adjetivo adverbio + preposición + adjetivo + sustantivo forma verbal + preposición + adjetivo + sustantivo

b) ¿̇abes de qué otra forma puede escribirse el sustantivo presente en esa estructura?

c) Comenta con tus compañeros sobre el significado de la frase hecha que se forma a partir de esa pareja de sustantivo y adjetivo.

d) ¿Cuál es el medio de transporte muy común en los campos de Cuba que se menciona en el fragmento?

e) ¿Conoces alguna expresión coloquial que se forme con ese sustantivo? Comenta su significado con tus compañeros y comparte si conoces otra frase con igual sentido.

f) ¿̇e corresponde la forma de tratamiento presente en este fragmento con las del resto del texto? ¿A qué crees que se deba el cambio?

Descripción de la actividad: el ejercicio permite mostrarles a los alumnos términos que se escriben de dos formas, como es el caso de hierba/yerba; también hacer referencia a que la posición del adjetivo, con respecto al sustantivo, influye en el significado de la frase. Facilita el trabajo con el refranero cubano. De igual forma posibilita insertar contenidos culturales relacionados con el uso del caballo como medio de transporte típico de los campos cubanos, así como conocer algunas expresiones idiomáticas creadas con este sustantivo.

Con el desarrollo del inciso f) se persigue abordar el uso del tú y usted, con el objetivo de que el estudiante consolide las circunstancias en las que se emplea el tuteo. 
Actividades posteriores a la lectura

16. Completa el siguiente recuadro con los vocablos del texto referidos a la flora, la fauna y los espacios físicos del campo.

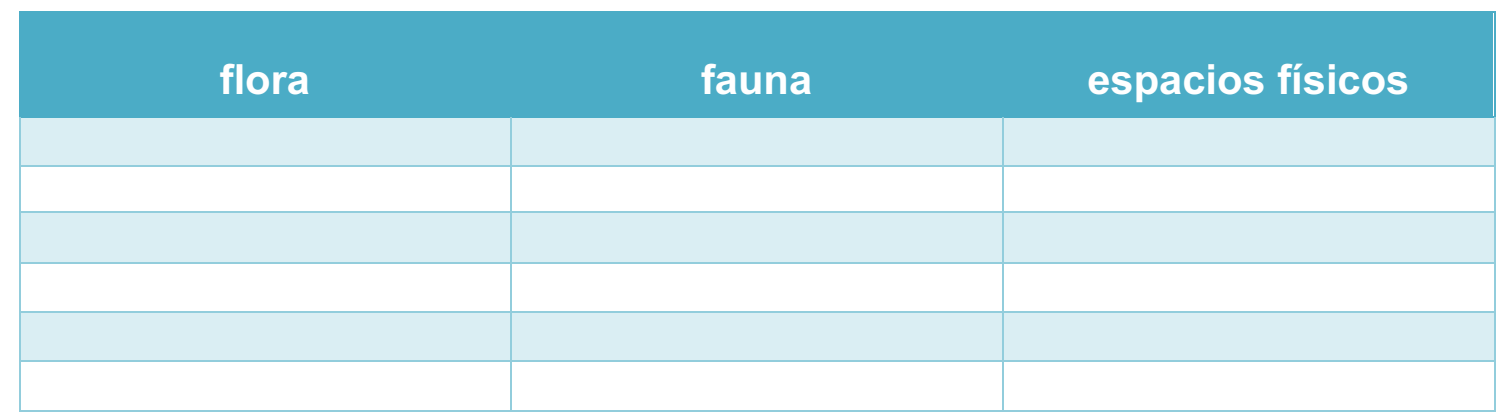

a) Busca el significado de los términos desconocidos por ti.

b) ¿Con qué intención son empleados los vocablos del recuadro?

c) Menciona otros sustantivos que caractericen al campo cubano.

d) Describe, en un párrafo, al campo típico de tu país. Emplea algunos hiperónimos con sus respectivos hipónimos.

e) Refiérete al sustantivo que denota el producto agrícola por excelencia del campo cubano. Explica su importancia para la economía del país. Como estudio independiente investiga con qué otra acepción se emplea este término en el lenguaje coloquial.

f) Escribe sustantivos que pertenezcan a la familia de caña, maíz y caminante.

Descripción de la actividad: el ejercicio permite el trabajo con el vocabulario relacionado con la naturaleza y la geografía cubana. Con el desarrollo del inciso e) se hace referencia a la caña de azúcar como uno de los renglones económicos de Cuba. Con la orientación del trabajo independiente se pretende que los estudiantes, al abordar la polisemia de este vocablo, incorporen nuevas expresiones del lenguaje coloquial. Se fomenta la producción escrita.

El inciso f) se desarrollará en forma de juego, de la siguiente manera: se divide el grupo en tres bandos y se selecciona un representante de cada uno. Los seleccionados deben escoger una tarjeta y buscar en el texto un vocablo que pertenezca a la familia de palabras de la que aparece en su tarjeta (las opciones serán maíz/maizal, cañas/cañaverales, camino/caminante). Una vez que lo encuentren deben dirigirse a la pizarra y redactar una oración con el término hallado. Gana el que termine primero, siempre y cuando realice correctamente la actividad. 
Este ejercicio fomenta la expresión oral y escrita. Su carácter lúdico contribuye a que los estudiantes actúen de forma desinhibida y, además, consolida el trabajo en equipo.

17. Escucha atentamente al profesor. Repite la frase pero añade siempre una nueva palabra relacionada con el tema desarrollado y atendiendo a que la frase tenga sentido. Luego otro compañero repetirá lo dicho por el profesor y por ti y aportará una nueva palabra y así sucesivamente sucederá con todos los miembros del grupo. Cuando se rompa la cadena pueden iniciar con otra frase. Ejemplo:

Profesor: En los campos cubanos hay...

Estudiante: En los campos cubanos hay campesinos...

Descripción de la actividad: este ejercicio de carácter lúdico contribuye a la ejercitación de la memoria a corto plazo. La realización del mismo demanda toda la atención del estudiante y sirve, además, para combinar y consolidar todo lo aprendido en la clase.

18. Completa la agenda de la muerte escribiendo la hora delante de cada tarea. Recuerda precisar en qué horario del día se llevarán a cabo.

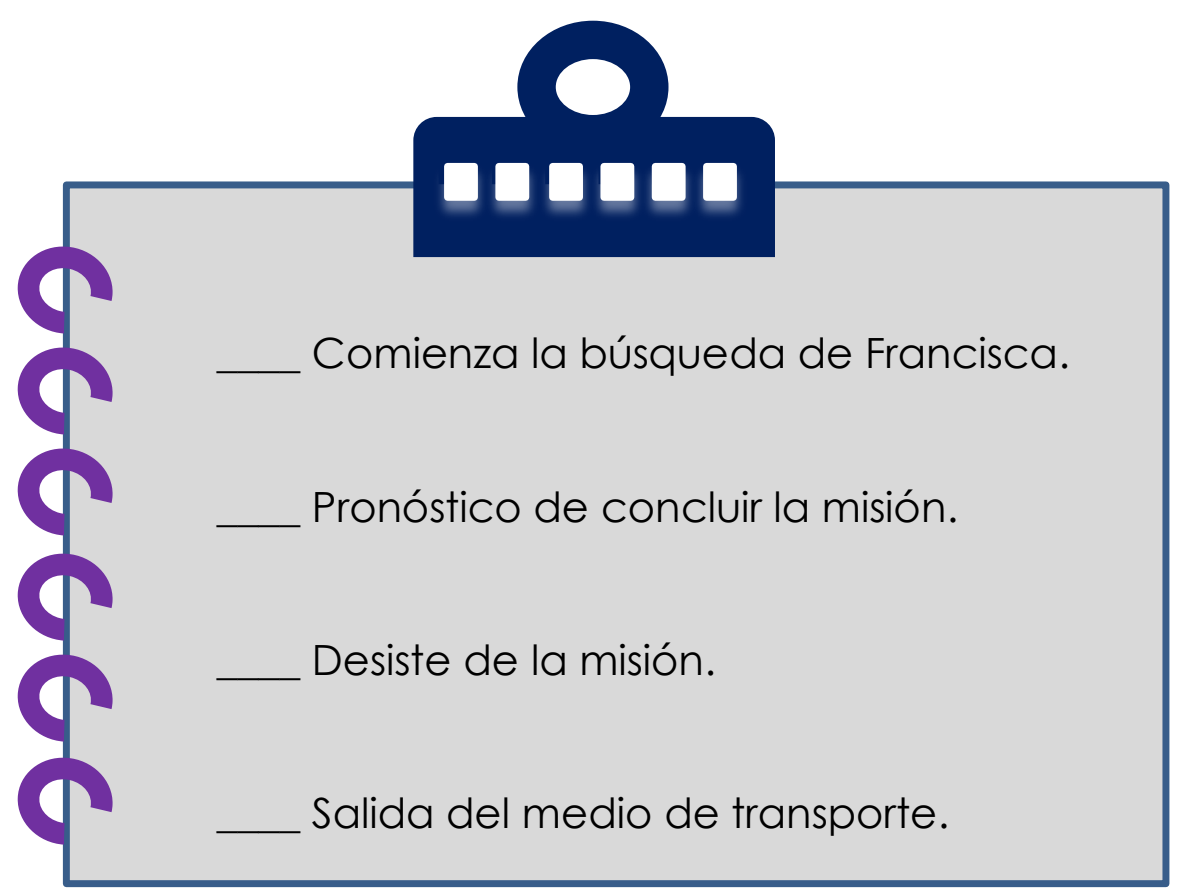

a) ¿¿Qué vocablos se han empleado en el texto para hacer alusión a distintos momentos del día? Expresar la hora equivalente de cada uno. 
Descripción de la actividad: el ejercicio posibilita el trabajo con la expresión de las horas, mediante la escritura numérica de los ejemplos que aparecen en el texto. A través de esta correspondencia se persigue la familiarización del alumno con las abreviaturas a.m. y p.m. y su significado. De igual forma se trabajan las expresiones amanecer y anochecer con el objetivo de que el alumno establezca comparaciones en cuanto a la hora en que suceden estos eventos en las distintas regiones.

\section{Apoyándote en el argumento del cuento realiza un mapa con la trayectoria realizada por la muerte para encontrar a Francisca.}

Descripción de la actividad: el ejercicio propicia la creatividad de los estudiantes. Sobre todo, permite comprobar si comprendieron el texto. Se puede realizar de forma individual o grupal.

\section{Identifica los verbos con pronombres proclíticos y enclíticos.}

a) Clasifícalos.

b) Investiga su forma de uso en las diferentes regiones de Cuba.

Descripción de la actividad: el ejercicio sirve de motivo para hacer alusión a al uso indistinto de los pronombres enclíticos y proclíticos. La preferencia en cuanto a su uso está regido por las diferencias diatópicas. Puede ilustrarse dichas diferencias a través de otros ejemplos. Se fomenta el trabajo independiente.

\section{Conclusiones}

El sistema de ejercicios propuesto, concebido desde el enfoque, cognitivo, comunicativo y sociocultural, propicia una participación activa y consciente por parte del alumno, al vincular sus vivencias y experiencias con el contenido que está recibiendo; del mismo modo que concibe los aspectos gramaticales, no como meros conceptos abstractos, sino como elementos determinados que cumplen una función específica en cada acto comunicativo. Esta propuesta didáctica constituye una guía para la elaboración de ejercicios bajo el enfoque cognitivo, comunicativo y sociocultural.

\section{Bibliografía}

ALBALADEJO, M. D. (2007): «Cómo llevar la literatura al aula de ELE: de la teoría a la práctica». MarcoELE. Revista de didáctica ELE No. 5. ISSN 1885-2211.

AVENTÍN, A. (2005): «El texto literario y la construcción de la competencia literaria en E/LE. Un enfoque interdisciplinario». Espéculo. Revista de Estudios Literarios, 29. 
BERNÁ, E. (2013): La cultura narrada. La leyenda tradicional como input cultural en la clase de E/LE. Reflexiones teóricas, análisis de materiales y propuesta didáctica. Tesis de maestría. Universidad de Alicante. Disponible en: http://rua.ua.es/dspace/handle/10045/35655

BERNAL, M. J. (2011): La literatura en el aula de E/LE. Trabajo fin de máster. Universidad de Salamanca. Disponible en: https://www.academia.edu/19424995/La literatura en el aula de E LE Trabaj o Fin de M\%C3\%Alster

CARDONA, A. (2014): "Enseñanza del español lengua extranjera a través de la literatura». Diálogos Latinoamericanos, 22, junio-enero, pp. 129-152.

Centro Virtual Cervantes. Plan Curricular del Instituto Cervantes. Niveles de referencia para el español. Disponible en: http://cvc.cervantes.es/ensenanza/biblioteca_ele/plan_curricular/default.htm (consultado: 28 marzo 2018).

DUEÑAS, O. (2012): Propuesta de un sistema de ejercicios, basado en el enfoque cognitivo, comunicativo y sociocultural, para el tratamiento de la ortografía puntual en la asignatura Gramática Española II, de la Licenciatura en Lengua Española para No Hispanohablantes. Tesis de maestría. Universidad de La Habana. Inédito.

DURÁN, G. (2010): Propuesta de un análisis linguo-textual para favorecer el desarrollo de la competencia literaria en Español como Lengua Extranjera. Tesis de maestría. Universidad de Oriente. Santiago de Cuba. Inédito.

FUNES, A. L. (2012): «El microrrelato en aula ELE. Aplicación didáctica». marcoELE. Revista de Didáctica Español Lengua Extranjera, 15, 1-64.

JOUINI, K. (2008): «El texto literario en la clase de español como lengua extranjera: propuestas y modelos de usolı. Íkala, revista de lenguaje y cultura Vol. 13, No. 20 (jul-dic), pp. 121-159.

LÓPEZ, E. (2009): El texto literario en el aula de español como lengua extranjera. Propuesta de programación didáctica: Últimas tardes con Teresa, de Juan Marsé. Tesis de maestría. Universidad de Girona. Disponible en: https://dugidoc.udg.edu/bitstream/handle/10256/1507/lopez pratsencarna.pdf? sequence=1

MEDINA, M. C. (2008): La competencia cognitiva, comunicativa, sociocultural, un importante contenido transversal en el Curso Preparatorio de la EIEFD (Cuba). Disponible en: www.monografias.com

MENOUER W. (2009): La literatura como recurso didáctico en la clase de E/LE. Actas del I Taller Literaturas Hispánicas y E/LE. Servicio de publicaciones: Almagro, pp.13-18.

Disponible

en: https://cvc.cervantes.es/ensenanza/biblioteca_ele/publicaciones_centros/PDF /oran_2009/13_fouatih.pdf

PINAR, A. G. (2012): «Cultura y publicidad en la clase de ELE. Propuesta didáctica para un curso de conversación». Suplementos MarcoELE, núm. 14. 
ROMÉU, A. et al. (2003): Acerca de la enseñanza del Español y la Literatura. La Habana: Editorial Pueblo y Educación.

- (2006): El enfoque cognitivo, comunicativo y sociocultural en la enseñanza de la lengua y la literatura. La Habana: Editorial Pueblo y Educación.

SANZ, M. (2006): «Didáctica de la literatura: el contexto en el texto y el texto en el contextor. Carabela, 59, pp. 5-23.

- (2002): «La literatura en el aula de E/LE». Frecuencia-L. Madrid, julio. pp. 24-27.

SITMAN, R. \& I. LERNER (1994): Literatura hispanoamericana: herramienta de acercamiento cultural en la enseñanza del español como lengua extranjera. Tendencias actuales en la enseñanza del español como lengua extranjera I: actas del quinto Congreso Internacional de ASELE. S. MONTESA PEYDRÓ Y P. GOMIS BLANCO (eds.). Málaga: Asele, pp. 227-234.

STEMBERT, R. (2009): «Propuestas didácticas de los textos literarios en la clase de E/LE». Monográficos MarcoELE, No. 9, pp. 247-265.

TOLEDO, A. (2006): El tratamiento de los contenidos gramaticales con un enfoque cognitivo, comunicativo y sociocultural. El enfoque cognitivo, comunicativo y sociocultural en la enseñanza de la lengua y la literatura. A. ROMÉU (comp.) La Habana: Pueblo y Educación, pp. 206-232.

VERGARA， N. (2006): «La literatura en E/LE: cuentos breves y desarrollo de la interculturalidad en el aula de E/LE). Memoria del Máster en Enseñanza del Español como Lengua Extranjera. Universidad Antonio de Nebrija. Biblioteca redELE, No $6 . \quad$ Disponible en: http://www.educacionyfp.gob.es/dam/jer:2457fbb9-9c1 1-4965-965cd623c6e10331/2006-bv-06-15vergara-pdf.pdf 


\section{Anexo 1}

Francisca y la muerte

Texto: Onelio Jorge Cardoso

Tomado de: Biblioteca Digital de Instituto Latinoamericano de la Comunicación

Educativa. Disponible en: http://www.ilce.edu.mx/

-Santos y buenos días — dijo la muerte, y ninguno de los presentes la pudo reconocer.

¡Claro!, venía la parca con su trenza retorcida bajo el sombrero y su mano amarilla en el bolsillo.

—Si no molesto — dijo-, quisiera saber dónde vive la señora Francisca.

-Pues mire -le respondieron, y asomándose a la puerta, un hombre señaló con su dedo rudo de labrador:

Allá por los matorrales que bate el viento, ¿̇ve? hay un camino que sube la colina. Arriba hallará la casa.

"Cumplida está" pensó la muerte, y dando las gracias echó a andar por el camino aquella mañana que, precisamente, había pocas nubes en el cielo y todo el azul resplandecía de luz.

Andando pues, miró la muerte la hora y vio que eran las siete de la mañana. Para la una y cuarto, pasado el meridiano, estaba en su lista cumplida ya la señora Francisca.

"Menos mal, poco trabajo; un solo caso", se dijo satisfecha de no fatigarse la muerte y siguió su paso, metiéndose ahora por el camino apretado de romerillo y rocío.

Efectivamente, era el mes de mayo y con los aguaceros caídos no hubo semilla silvestre ni brote que se quedara bajo tierra sin salir al sol. Los retoños de las ceibas eran pura caoba transparente. El tronco del guayabo soltaba, a espacios, la corteza, dejando ver la carne limpia de la madera. Los cañaverales no tenían una sola hoja amarilla; verde era todo, desde el suelo al aire, y un olor a vida subía de las flores.

Natural que la muerte se tapara la nariz. Lógico también que ni siquiera mirara tanta rama llena de nidos, ni tanta abeja con su flor. Pero żué hacerse?; estaba la muerte de paso por aquí, sin ser su reino.

Así pues, echó y echó a andar la muerte por los caminos hasta llegar a casa de Francisca.

-Por favor, con Panchita — dijo adulona la muerte.

-Abuela salió temprano — contestó una nieta de oro, un poco temerosa, aunque la parca seguía con su trenza bajo el sombrero y la mano en el bolsillo.

- ¿Y a qué hora regresa? —preguntó la muerte.

— ¡Quién lo sabe! — dijo la madre de la niña-. Depende de los quehaceres. Por el campo anda, trabajando. 
Y la muerte se mordió el labio. No era para menos seguir dando rueda por tanto mundo bonito y ajeno.

-Hace mucho sol. ¿ेPuedo esperarla aquí?

- Aquí quien viene tiene su casa. Pero puede que ella no regrese hasta el anochecer.

"¡Contra!", pensó la muerte, "se me irá el tren de las cinco. No; mejor voy a buscarla". Y levantando su voz, dijo la muerte:

— ¿Dónde, al fijo, pudiera encontrarla ahora?

—De madrugada salió a ordeñar. Seguramente estará en el maíz, sembrando.

- ¿Y dónde está el maizal? -preguntó la muerte.

- Siga la cerca y luego verá el campo arado detrás.

-Gracias - dijo seca la muerte y echó a andar de nuevo.

Pero miró todo el extenso campo arado y no había un alma en él. Sólo garzas. Soltóse la trenza la muerte y rabió:

"¡Vieja andariega, dónde te habrás metido!" Escupió y continuó su sendero sin tino.

Una hora después de tener la trenza ardida bajo el sombrero y la nariz repugnada de tanto olor a hierba nueva, la muerte se topó con un caminante:

- Señor, ¿̇pudiera usted decirme dónde está Francisca por estos campos?

-Tiene suerte — dijo el caminante-, media hora lleva en casa de los Noriega. Está el niño enfermo y ella fue a sobarle el vientre.

-Gracias — dijo la muerte como un disparo, y apretó el paso.

Duro y fatigoso era el camino. Además, ahora tenía que hacerlo sobre un nuevo terreno arado, sin trillo, y ya se sabe cómo es de incómodo sentar el pie sobre el suelo irregular y tan esponjoso de frescura, que se pierde la mitad del esfuerzo. Así por tanto, llegó la muerte hecha una lástima a casa de los Noriega:

-Con Francisca, a ver si me hace el favor.

-Ya se marchó.

- ¡Pero, cómo! ¿̇sí, tan de pronto?

- ¿Por qué tan de pronto? -le respondieron-.

Sólo vino a ayudarnos con el niño y ya lo hizo. ¿¿De qué extrañarse?

—Bueno... verá — dijo la muerte turbada-, es que siempre una hace la sobremesa en todo, digo yo.

-Entonces usted no conoce a Francisca.

-Tengo sus señas — dijo burocrática la impía.

- A ver; dígalas —esperó la madre. Y la muerte dijo:

- Pues... con arrugas; desde luego ya son sesenta años...

- ¿Y qué más? 
—Verá... el pelo blanco... casi ningún diente propio... la nariz, digamos...

- ¿̇igamos qué?

-Filosa.

- ¿Eso es todo?

—Bueno... además de nombre y dos apellidos.

-Pero usted no ha hablado de sus ojos.

—Bien; nublados... sí, nublados han de ser... ahumados por los años.

-No, no la conoce - dijo la mujer-.

Todo lo dicho está bien, pero no los ojos. Tiene menos tiempo en la mirada. Ésa, a quien usted busca, no es Francisca.

Y salió la muerte otra vez al camino. Iba ahora indignada sin preocuparse mucho por la mano y la trenza, que medio se le asomaba bajo el ala del sombrero.

Anduvo y anduvo. En casa de los González le dijeron que estaba Francisca a un tiro de ojo de allí, cortando pastura para la vaca de los nietos. Mas sólo vio la muerte la pastura recién cortada y nada de Francisca, ni siquiera la huella menuda de su paso.

Entonces la muerte, quien ya tenía los pies hinchados dentro de los botines enlodados, y la camisa negra, más que sudada, sacó su reloj y consultó la hora:

"¡Dios! ¡Las cuatro y media! ¡Imposible! ¡Se me va el tren!"

Y echó la muerte de regreso, maldiciendo.

Mientras, a dos kilómetros de allí, Francisca escardaba de malas hierbas el jardincito de la escuela. Un viejo conocido pasó a caballo y, sonriéndole, le tiró a su manera el saludo cariñoso:

-Francisca, żcuándo te vas a morir?

Ella se incorporó asomando medio cuerpo sobre las rosas y le devolvió el saludo alegre:

—Nunca — dijo—, siempre hay algo que hacer. 